\title{
Neonatal Respiratory Insufficiency, AE
}

National Cancer Institute

\section{Source}

National Cancer Institute. Neonatal Respiratory Insufficiency, AE. NCI Thesaurus. Code C154951.

An adverse event in a newborn characterized by significant impairment of gas exchange resulting in compensatory breathing efforts and eventually hypoxia and/or hypercarbia. Note: Consider this adverse event for any patient whose respiratory condition deteriorates from baseline. If any specific diagnosis is identified: use diagnosis-specific scale (e.g. respiratory distress syndrome (RDS), pulmonary hemorrhage). 